\title{
Improving Learning Outcomes of Ecological Concept Using Scaffolding Strategy on Scientific Approach
}

\author{
Nur Wakhidah ${ }^{1, *}$ \\ ${ }^{1}$ State Islamic University, Surabaya, Indonesia \\ *Corresponding author: State Islamic University, Surabaya, Indonesia. E-mail: \\ nung.ae8@gmail.com
}

Received: September 12, 2016 Accepted: October 10, 2016 Published: February 1, 2017

doi:10.5296/ije.v9i1.10020ＵRL: https://doi.org/10.5296/ije.v9i1.10020

\begin{abstract}
Learning about the environment for prospective teachers in public primary schools with the lecture method does not equip students how the direct impact of pollution on aquatic organisms and provide little opportunity for undergraduate students learn design of experiments. This study aims to assess the use of scaffolding strategies IMWR (inspiring-modeling-writing-reporting) on the scientific approach to improving the mastery of concepts. The study was conducted in the department of elementary education from the State Islamic University Sunan Ampel Surabaya Indonesia. Students are given a pretest before the next lesson scaffolding strategy applied on the scientific approach and given a post-test after the lesson. The data recorded is the improvement of learning outcomes, implementation strategies IMWR in the learning process with a scientific approach, and the response from students about learning. Data analysis was performed to determine learning outcomes by calculating the gain $\mathrm{n}$ (gain normalized). The results showed that the use of scaffolding strategies IMWR on the scientific approach can improve environmental concept with $n$ gain of 0.68 (medium category), implementation of the strategy IMWR goes well, and the positive response from the students after learning.
\end{abstract}

Keywords: scaffolding strategy, scientific approach, learning outcomes 


\section{Introduction}

Development in science and technology, population growth and the increasing needs can take of the natural resources that could potentially damage the environment. Damage to the environment is not just the responsibility of government and society but also the responsibility of all elements of society, including educational institutions. Primary prospective teachers must take learning about the environment so they can teaching about environmental components and impact if there is damage.

Learning about concept of environmental pollution with lectures and discussions are less effective, as students become less active, even when the discussion is only a few students who are actively involved in the discussion. The scientific approach in Curriculum 2013 in Indonesia is expected can enable all students in the process of observing, asking questions, trying, reasoning and communicating. Implementation of scientific approach in learning is still a lot of obstacles. Students and lecturers are less familiar with scientific approach so implementation this approach in learning process does not good.

The difficulty in using a scientific approach occurs for several reasons including the lack of facilities in PGMI Department of State Islamic University Sunan Ampel. The role of the lecturer is less than optimal in presenting the phenomenon at early so that students are less motivated to learn more by asking questions so that students do not have the opportunity to learn designing of experiments and this skill is very important when teaching later.

Wakhidah (2016) has developed a strategy scaffolding IMWR (inspiring-modeling-reporting-writing) on a scientific approach in learning process. This strategy will inspire current students to observe, ask questions, trying (experiment), data analysis, and communicate. Student who is not inspired will be given example by the lecturer (modeling). Students are given the opportunity to mimic the behavior of modeling by writing in all steps of the scientific approach. In the end, the students reported the process of mimicking all the steps of the scientific approach to determine whether a skill that is a step of the scientific approach has been mastered. Students who have been able to observing given the opportunity to ask questions and so on.

\section{Literature Review}

\subsection{The Scientific Approach in Learning Process}

The scientific approach is one approach recommended by Indonesian Curriculum. This approach uses the scientific method to acquire new knowledge by integrating prior knowledge (Carey, 2001). Learning with scientific approach is an active learning process through the stages of observing, collecting data, analyzing data, drawing conclusions, and communicating concepts. Steps of scientific approach is part of the science process skills (Karar \& Yenice, 2012). The scientific approach has been used on the 19th century American curriculum (Rudolph, 2005) and has been used in the Indonesian curriculum is known as an active way of learning (Varelas and Ford, 2009). Learn with a scientific approach provides an 
opportunity for students to build knowledge. Learning is essentially a process of building knowledge (Jena, 2012). The learning process should start from the issues that are relevant to the life of (the American Association for the Advancement of Science, 1989). Lecturers should facilitate students in connecting the knowledge that has been owned by the students with the material to be studied and provide the opportunity to design and conduct experiments (Slavin, 2006).

Traditional learning process less gives students the opportunity to build knowledge (Akamca et al, 2009). Learning process with scientific approach gives student opportunity to build knowledge with inspiring strategy (Wakhidah, 2016) so the student can relating concept and their world. The knowledge possessed by students are usually related to the context or prior experience and contextual learning provides an opportunity for students to connect with other concepts or in other situations (Smith, 2010). Step-by-step scientific approach in learning is observing, asking questions, try to answer questions, data analysis, and communicating.

Moreno (2010) says that observing process can occur on objects real or simulated. Xu et al (2012) and Slavin (2006) says that the stimulus provided to students have the shape of a picture or an interesting phenomenon in accordance with the material (Slavin, 2006). Someone will learn better when the media used in learning process is a combination of verbal and nonverbal channels channel (Najjar, 2005) so that the information submitted can be absorbed properly.

Lecturers should show some of the phenomena associated with the concept. This observation process is very important because it can encourage students to ask questions after viewing a picture or a brief description of the lecturer. Questions can occur spontaneously by the response of students (Chin, 2002). Activity observing in learning can also be done through seeing, hearing, and reading. At this stage other than to increase the curiosity of students also give students an opportunity to think based on the experience they have. Failure to observe can affect the next process (asking question) so that the lecturers have to provide a scaffolding.

Observing, asking questions, trying, analyzing and communicate can develop creativity, curiosity, and have critical thinking in the context of lifelong learning (Ministry of Education, 2013). Asking questions is an important part of the process of scientific research (Brill and Anat, 2003). Lecturers must give students the opportunity to ask questions to develop want to know which is the intrinsic motivation to learn (Jirout \& Klahr, 2011). Scaffolding must be planned prior to the learning process (Chin, 2001). According to Chin (2002) asking the question means that a student thought to build knowledge (Chin et al, 2002). Questions of students can arise when there is discrepant events so appear kognitive conflict. Character of question may be clarify previous concept or something new and unique. Lecturers should stimulate students with the original question (Miao, 2012). Chin \& Brown (2000) reported that the initial questions can help students make hypotheses, predict, and designing experiments.

One way to collect the information suggested in Curriculum 2013 through experimentation, reading other sources, and interviews with informants. Learning with experiment can 
increases retention of learning. Beydogan (2001) stated that students that learn with conduct experiments will enhance the understanding of up to $90 \%$. Lecturers need to give scaffolding when students difficulty of designing and conducting experiments (Atsnan and Rahmita, 2013). The role of the lecturer facilitates students in gathering information or designing experiments.

Reasoning or association or data analysis to find information about the relationship with other information, which is a process of logical thinking on empirical data to make conclusion. Conclusion is constitute concept that found by student in the form of new knowledge. Communication is very important because it is the 21st century skills. These skills are important for prospective teachers so that they can interact with other students in reviewing the material being studied. Theory Vygotskian emphasize on social learning, in which the cognitive abilities of humans comes from social interaction of each individual in a cultural context so that the learning that occurs when learners work or handle tasks that are being studied in the zone of proximal development of students (Slavin, 2006), Howe (2006) stated that the concept can not be built without social interaction.

\subsection{Scaffolding}

Definition of scaffolding in learning, according to the experts is) help lecturer if needed and removed when not needed (Lajoie, 2005), b) platform help to build knowledge (Alake, 2013), c) the assistance provided in the development zone of proximal learners ( Hogan \& Pressley, 1997), d) the support provided by teachers, colleagues, or other resources in the zone of proximal development (Vygotsky, 1978; Miao (2012), e) the instructions, reminders, encouragement, steps, provide an example, allows one to grow up to be independent (Slavin, 2006).

Zone of proximal development (ZPD) was created by Vygotsky (1978) to describe the area that could be done by learners themselves (actual) and that can not be done without the help of a more capable (Fretz et al, 2002). Scaffolding given at the beginning and reduced until independently (Rosenshine \& Meister, 1992), and can be done by tutors, lecturers / teachers, parents, peers, tools, and methods (Lajoie, 2005). Students work together to help each other in learning (Slavin, 2006; Hurley \& Chamberlain, 2003).

Scaffolding in the learning process has unwittingly done by teachers, but the mentioned technical assistance was not named. Alber (2014) found the scaffold technique that provided for students namely show and tell, tap in to prior knowledge, pre-teach vocabulary, using visual aids and give pause, ask questions, pause, review.

The scientific approach in learning based on evidence in the field can not be applied optimally (Wicaksono, 2013), so it requires a strategy for implementing it, and students practice finding concept through learning. The idea of the learning process has recently emphasized that learners are involved in planning, implementation and used of scaffolding in the investigation to found the concept (Sandoval and Reiser, 2003).

Strategies are steps that can facilitate students to achieve higher performance (Rosenshine and Meister, 1992). The strategy here mean the steps to help students apply the scientific 
approach on learning. Miao (2012) suggest that scaffolding strategies may assist learners in making observations, asking questions, trying, analyzing data, and communicate so that students can discover the concept through learning process.

Step-by-step of scientific approach in fact actually the science process skills namely observing, ask questions, trying out, analyze, and communicate. IMWR (inspiring-modeling-writing-reporting) is scaffolding strategies to helping students implementing each step of the scientific approach (Wakhidah 2016). Students who have not been inspired implementing each step of the scientific approach will be modeled by lecturer. Furthermore, students imitate skills that modeled through activity of writing and reporting skills that have been mastered. Every step of the scientific approach will be assisted by inspiring from lecturer, modeling by lecturer, followed with write the modeling results by students, and finally student asked to report it. For example on step of observing, lecturer will be inspire a student to observing, if the student has not been able to observing with inspiring from lecturer the next will be modeling by lecturer how observing well, after which the student imitate modeling of lecturer with write result of observing, and then report observations. The same thing to steps of scientific approach namely ask question, trying to answer question, analysis with relevant theory, and communicate the concepts that found.

\section{Method}

Subjects were student prospective teachers of UIN Sunan Ampel Surabaya Indonesia as many as 12 people. Before learning with the strategy of scaffolding on the scientific approach are given a pretest to check the student environment concept. Learning with scaffolding IMWR strategy on scientific approach include: students college inspired by scaffolding with (inspiration) at every step of the scientific approach. Students college who are not inspired given modeling, for example, how to observe, and then imitating to observing (writing observations) and report their skills (reporting). At every step of the scientific approach: observing, asking questions, trying to answer, the analysis with relevant theory, and communicate the concepts generated by scaffolding IMWR (inspiration-modeling-writing reporting). After learning with scaffolding IMWR on scientific approach given the ultimate test. The tests used the same as the pretest in terms of material and the same difficulty level.

\section{Result of Research}

\subsection{Result}

The results showed that the use of scaffolding strategies IMWR on scientific approach is effective to improve learning outcomes. The proportion of the test results and n-gain can be seen in Table 1. 
Table 1. Improved Student Outcome after Applying Scaffold Strategies IMWR

\begin{tabular}{lrrr}
\hline Code of Student & Proportion of pretest & Proportion of posttest & \multicolumn{1}{c}{ n-gain } \\
\hline 1 & 0.09 & 0.85 & $0.84(\mathrm{~h})$ \\
2 & 0.09 & 0.75 & $0.73(\mathrm{~h})$ \\
3 & 0.05 & 0.7 & $0.68(\mathrm{~m})$ \\
4 & 0.62 & 0.75 & $0.34(\mathrm{~m})$ \\
5 & 0.65 & 0.85 & $0.57(\mathrm{~m})$ \\
6 & 0.66 & 0.9 & $0.71(\mathrm{~h})$ \\
7 & 0.61 & 0.95 & $0.87(\mathrm{~h})$ \\
8 & 0.75 & 0.95 & $0.8(\mathrm{~h})$ \\
9 & 0.71 & 0.85 & $0.48(\mathrm{~m})$ \\
10 & 0.71 & 0.9 & $0.66(\mathrm{~m})$ \\
11 & 0.19 & 0.95 & $0.94(\mathrm{~h})$ \\
12 & 0.8 & 0.9 & $0.5(\mathrm{~m})$ \\
Average & 0.49 & 0.86 & $0.68(\mathrm{~m})$ \\
\hline
\end{tabular}

$\mathrm{h}=$ high $\quad \mathrm{m}=$ medium

Pretest and posttest results showed an increase learning outcomes with n-gain 0.68 (medium category). Enhancement student learning outcomes are shown in Figure 1.1.

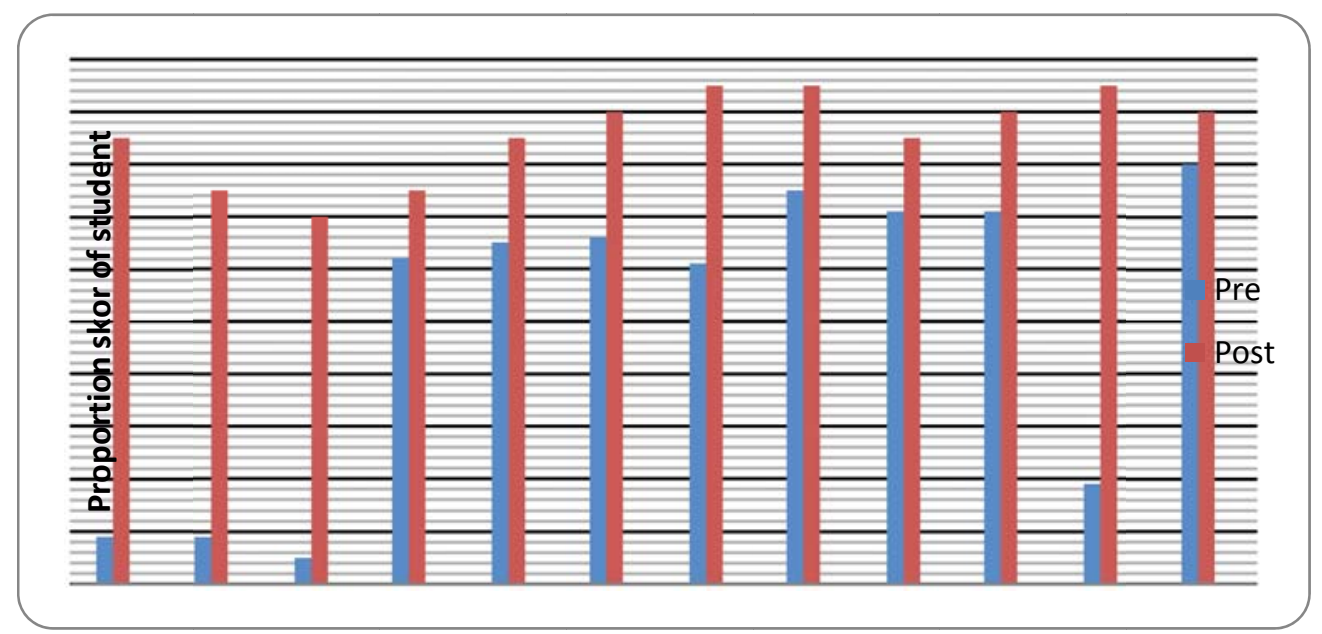

Figure 1. Increased Student Mastery of Knowledge Competence

The steps of the scientific approach is measured / assessed directly during the learning process. The average score for the skills of observation is 4 (all students were able to observe the phenomenon shown by lecturer), questioning skills obtained a score of 4 (all students were able to ask questions), a score of 3.97 for information gathering skills (students can design and gather information / experiment), analysis with relevant theory obtained a score of 3.58 (students have been able to associate the data with relevan theory), communication skills getting an average score of 3.78. This means that all the steps of a scientific approach in learning implemented well. The lowest score is the skill to analyze the data. These skills should continue to be trained in learning so that students gain a deeper understanding to found the concept. 
Analysis result with questioner, students are happy with the use of strategies IMWR on the scientific approach so that $92 \%$ students feel happy. Students are also pleased with the learning material learning (92\%) and worksheets used (92\%). The classroom atmosphere during the implementation of this strategy also fun for $83 \%$ and students feel happy, including learning model used (83\%).

\subsection{Discussion}

Step IMWR strategy can be observed and implemented in learning process with scientific approach. This means that the strategy IMWR practical to apply a scientific approach in accordance with the steps of scientific approach. Miao (2012) states that the scaffolding strategy is expected to help learners to observe, ask questions, gathering information, analyze data, and communicate data as a form of understanding of the concept.

Scaffolding strategies used in learning by using a scientific approach will make students more active in asking about, discuss, experiment, observation, and higher level thinking processes. Aknipar (2009) suggested that teachers should provide assistance to students in order to establish the relationship between the new concept with the previous concept.

Scaffolding is given by the lecturers to the students in the study of both individuals and groups. According Hofstei (2012) teachers should encourage students to interact with peers to solve problems and put forward the hypothesis. Vygoskian theory shows that in studying the concept needed the interaction between students and other students, students and teachers. Dresner et al. (2013) stated that the aid be dynamically adjusted to help students when observing, asking questions, trying, reasoning, and communication. Students in the same group give each scaffolding if any group members who do not understand. Lajoie (2005) states that the scaffold is not always done by the lecturers, but could be done by peers during discussions. Colleagues may be as a scaffolds in one group (Miao, 2012). According Lajoie (2005) scaffold by the lecturer will fading after not necessary and could be replaced by member of group.

Learning outcomes of student increasing after used IMWR strategy on the scientific approach. Score of posttest increasing with an increase in the average n-gain of 0.68 (medium category). Learning process with IMWR strategy can improve the mastery of concepts because students are given the opportunity to observe, discuss, design and conduct experiments, seek information, analyze data so that more meaningful learning and increase retention of understanding. Wiemann (2007) states that the scientific approach can encourage students to discover concepts through the process. Retention of understanding increased up to $90 \%$ when doing an activity (Beydogan, 2001).

Increased understanding of the students is also caused by IMWR strategy step during the discussion (reporting) and writing at each stage of the scientific approach. According to Keeling et al (2009) writes can increasing understanding. Writing is the third step of IMWR strategy after modeling by lecturer. Pol et al., (2010) stated that by doing modeling will increase students' cognitive abilities. Modeling is the second step of the strategy IMWR to improve understanding. Dresner et al., (2013) stated that scaffold improve the retention of 
understanding and higher level thinking. Pol et al., (2010) adds that by doing modeling will increase students' cognitive abilities. Gaskins et al (1997) showed that the scaffold can be shaped guidance and modeling to assist learners in developing new skills or learning new concepts and if the learner has achieved the expected competencies such assistance can be eliminated. Lecturers can provide scaffolding for modeling, give feedback and provide opportunities for students to practice the tasks assigned. This is supported by research McNeill et al. (2005). Support to learn and solve problems in the form of instructions, reminders, encouragement, steps, provide examples, or other things allows one to grow into independent learners (Slavin, 2006).

Students respond positively to the use of scaffolding strategies IMWR on the scientific approach. This means students feel that the strategy used useful in learning to discover and understand the concept. Learning with scaffolding strategy IMWR, student feel a fun and all students motivated to doing discussions and searching for information or experiment. Presentation and reporting from result of writing on all step scientific approach can make the classroom atmosphere to be enjoyable.

\section{Conclusion}

Strategy scaffolding IMWR on the scientific approach can improve learning outcomes with n-gain 0.68 (medium category) and enhance understanding of students environment concept and its impact on life. Based on the results of research and discussion are suggested: scaffolding strategies IMWR need to be tested on materials or other concept in the learning process to find a concept, before using scaffolding strategy IMWR need providing a description or explanation of the steps a scientific approach to students so easily applied.

\section{Acknowledgement}

The research is financed by Islamic Development Bank and State Islamic University. Thanks for Prof. Muslimin Ibrahim and Prof. Rudiana Agustini, Surabaya State University who are encourage to my research.

\section{References}

Abdillah M. (2001). Sustainable Religion: Perspective of the Qur'an. Jakarta: Paramadina

Alake, E.M., \& Ogunseemi, O.E. (2013). Effects of Scaffolding Strategy on Learners' Academic Achievement in Integrated Science At The Junior Secondary School Level. European Scientific Journal, 9(19).

Alber, R. (2014). Scaffolding Strategies to Use With Your Students. USA: George Lucas Educational Foundation

American Association for the Advancement of Science (AAAS). (1989). Science for all 
Americans. New York: Oxford University Press.

Chin, C. (2001). Learning in Science: What Do Students' Questions Tell Us About Their Thinking? Education Journal, 29(2).

Chin, C. (2002). Student-Generated Questions: Encouraging Inquisitive Minds in Learning Science. Teaching and Learning, 23(1), 5947

Dresner, M., de rivera, C., Fuccillo, K.K., \& Chang, C. (2013). Improving Higher-Order Thinking And Knowledge Retention In Environmental Science Teaching. BioScience Advance Access publisher

Fretz, E.B., Hsin, K.W., Baohui, Z., Elizabeth, A.D., \& Joseph, S.K. (2002). An investigation of scaffolds supporting software modeling practices. Research in Science Education, 32, 567-589. https://doi.org/10.1023/A:1022400817926

Howe, A. (2006). Development of Science Concept within Vygotskian Framework. Science Education. Singapore: John Wiley and Son.

Jirout, J., \& Klahr, D. (2011). Children's Question Asking And Curiosity: A Training Study. Fall 2011 SREE Conference Abstract Template.

Lajoie, S.P. (2005). Extending the scaffolding metaphor. Instructional Science, 33, 541-557. https://doi.org/10.1007/s11251-005-1279-2

Miao, Y., Jan, E., Adam, G., Stefan \& Ulrich, H. (2012). Develoment of a process-oriented scaffolding agent in an open-ended inquiry learning environment. Research and Practice in Technology Enhanced Learning, 7(2), 105-128.

Moreno, R. (2010). Educational Psychology. USA: John Wiley \& Sons, Inc.

Najjar, L. J. (2005). A Review of the Fundamental Effect of Multimedia Graphic, Visualization, and Usability Laboratory. Atlanta: Georgia Institute of Technology. Retrieved October 3, 2012 from http://www.cc.gatech.edu/gvu/

Rosenshine, B., \& Meister, C. (1992). The use of scaffolds for teaching higher-level cognitive strategies. Educational Leadership, 49(7), 26-33.

Slavin, R.E. (2006). Educational Psycology.Theory and Practice. New Jersey: Pearson Educations Inc.

Smith, B.P. (2010). Instructional strategies in family and consumer sciences: implementing the contextual teaching and learning pedagogical models. Journal of Family \& Consumer Sciences Education, 28(1).

Wakhidah, N. (2016). Strategies Inspiring Scaffolding-Modelling-Writing-Reporting (IMWR) In Applying Scientific Approach To Improving Science Process Skills And Concepts Mastery Students. Draft Dissertation. Not Published.

Wieman, C. (2007a). A Scientific Approach to Science Education? Colorado: University of British Columbia. 


\section{Question}

Direction: Answer the questions below with a brief and clear!

1. Look at the picture below! identification of biotic and a biotic components (at least 3)

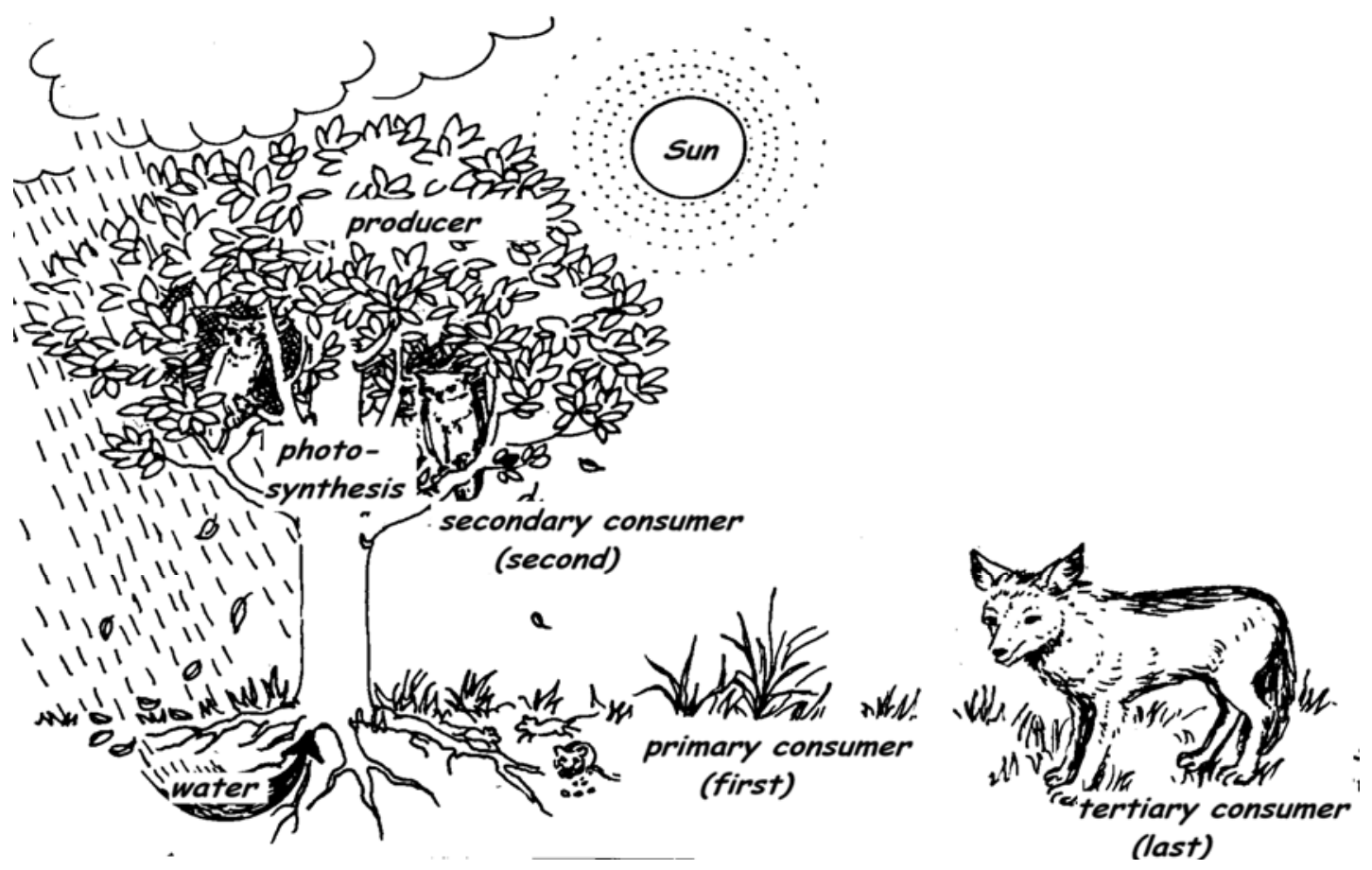

http://clipgid.com/forest-ecosystem-drawing.html

2. Consider the following picture!

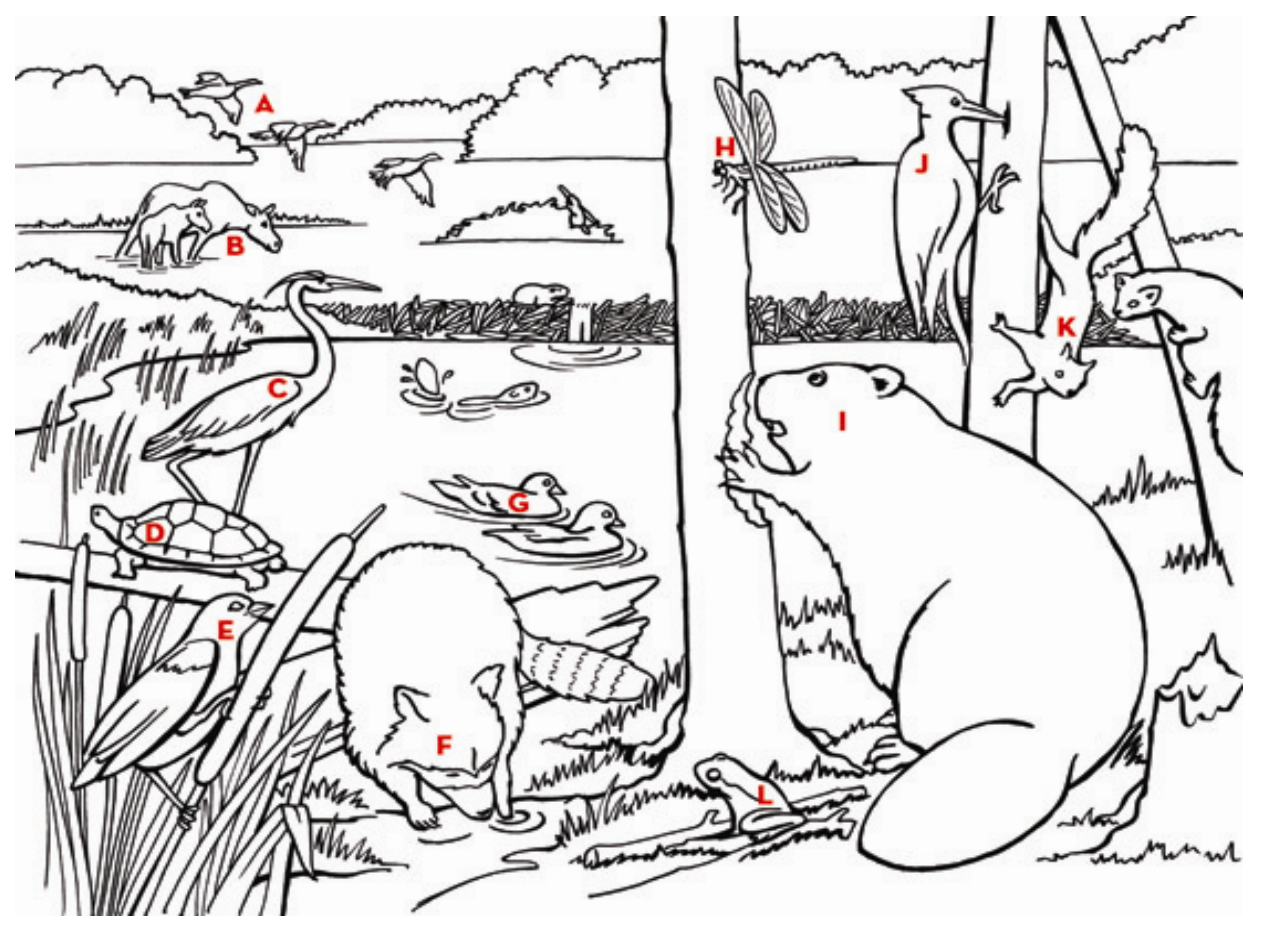


http://www.outsetmedia.com/coloringpuzzlestories

From the illustration above, look for a symbiosis between living beings what is possible and how symbiosis form do?

3. The areas of rice fields on the edge of the village found the grass plants, rabbits, mice, grasshoppers, fruit trees, owls, hawks, rice plants, sparrows and squirrels. From that information, make at least 4 of the information food chain that may occur in the area!

4. An area in the garden Biology extent of $100 \mathrm{~m}^{3}$, the weight of $3 \mathrm{~kg}$ of grass growing, there is a mango tree that has not been so great approx weighs $20 \mathrm{~kg}$. On top of that tree weaver 1000 ants, respectively $2 \mathrm{~g} /$ head. Black ants that exist on the ground are numbered as 50, 1 gr/head. Kacer birds on the mango tree, each weighing 50 grams. Calculate and describe the biomass pyramid!

5. How phosphorus recycle in an ecosystem? Explain!

\section{Copyright Disclaimer}

Copyright for this article is retained by the author(s), with first publication rights granted to the journal.

This is an open-access article distributed under the terms and conditions of the Creative Commons Attribution license (http://creativecommons.org/licenses/by/3.0/). 